\title{
Corruption in Sub-Saharan Africa - An Impediment to Economic Growth
}

\author{
Lamin Ceesay \\ BSc International Economics \& Trade \\ Nanjing University of Science and Technology, China
}

Doi:10.19044/esj.2019.v15n10p16 ～$\quad$ URL:http://dx.doi.org/10.19044/esj.2019.v15n10p16

\begin{abstract}
Sub-Saharan Africa is faced with many challenges. It is a region bulging with resources but cursed with incredible political and economic greed. With a vast ethnic diversity and an often misconstrued cultural lifestyle, which puts the region on the marginalization line. From a historical context, the impact of colonialism has haplessly set the environment for low leadership standards. The background setting for Sub-Saharan Africa's economic underdevelopment is uninhibited corruption that exists within Sub-Saharan African societies. This institutional corruption takes a triangular cause cultural, economic and political; each, together with so many other factors threaten Sub-Saharan Africa's socio-economic development.
\end{abstract}

Keywords: Economic under-development, Corruption, Sub-Saharan Africa (SSA)

\section{INTRODUCTION}

\section{Purpose of the study}

The causes for Sub-Saharan Africa's stagnant economic growth may well be an infinite number, but as previously mentioned in the abstract, this paper particularly attempts to assign insightful explanations to the corruption cause. Sub-Saharan Africa's economic presence at the global stage has often been an issue under continual discussions for many decades, particularly from the World Bank and IMF. The question of marginalization and engagement has often been the focal point.

A general consensus has it that Sub-Saharan Africa is one of the most corrupt places in the world, a factor that largely contributes to the stunted socio-economic growth in the region. A staggering $\$ 150$ billion is lost to corruption each year by driving away investments and high-value projects; as compared to a meagre $\$ 25$ billion of foreign aid to the region each year. This is evidence that the region's long term development goals come not from 
without (foreign aid) but from within, by putting strenuous efforts into fighting corruption. Political graft in the region accounts for the largest cost while small bureaucratic bribes undermine public trust in the government with hazardous effects on primary institutions.

Considering the avalanche of the related problems to slow economic growth in Sub-Saharan Africa, this paper critically analyses one of the primary causes - Corruption, which is apparently an unceasing cycle. Referencing to Dambisa Moyo's bestseller 'Dead Aid', Sir Edward Clay, a British special envoy to Kenya in 2004, commented: "ministers were eating like gluttons and vomiting on the shoes of foreign donors."

Corruption is perhaps the most talked about issue regarding the continent's pretty poor economic performance as compared to the rest of the world, though a few countries like Kenya and Rwanda are establishing the continent's presence in the international economy, with the former having recently launched a nationwide anti-corruption commission headed by renowned Professor and Public Speaker, Patrick Loch Otieno Lumumba. Most economic analysts undoubtedly agree that corruption tends to lower and stagnate economic growth, identifying two reasons to this detriment of sustainable economic growth. The weakness of the central governments takes primacy in this case. A weak central government leaves loopholes for other government agencies and bureaucracies to indulge in independent bribes. Bribery can be defined as another form of illicit taxation as a foreign investor or even a local has to offer bribes to numerous government agencies to acquire an operations license. These bribes increase the cumulative cost of operation, which lowers the incentive for foreign investment. The second important reason is the secrecy in corruption. Secrecy can shift investments away from high-value projects, towards lower value projects. The inherently secretive nature of corruption gives way to the choice of projects.

\section{Research Scope}

With a total of forty-six countries in Sub-Saharan Africa, inhabited by an almost staggering one billion people (certainly minimal compared to China and India) across its four geographical areas (East, West, Central, and South), with some few other islands laying out-land, the overall economic attribute is similar in almost all of SSA, other than some slight aberration. From a historical context of the scramble for Africa, the fragmentation has rendered certain countries like The Gambia, Togo, Benin, Rwanda, Burundi and Swaziland relatively small in area, while notable nations like Nigeria, Tanzania, Ethiopia, and DRC are larger in both area and population. This difference in size and population represent little or no difference in setting the pace for economic growth. South Africa, cited as one of the largest and most modern in the region, follows the general trend, because daily life and 
economic status of the average native South African in Soweto is nothing different compared to that of the average Gambian dwelling in the suburbs of Serrekunda, The Gambia.

\section{Research Method}

The majority part of this research dwells on objective analysis of the corruption cause, an impediment to economic growth in SSA. The research collects useful data as indicators to measure Sub-Saharan Africa's competitiveness with the rest of the world. Independent analyses of the proposed cause are then carried out to devise constructive longterm propositions to SSA's slow economic growth. The secrecy that is inherent in corruption breeds in a certain degree of difficulty in addressing the problem.

\section{Research Findings}

The fundamental findings of this paper are that while the significant number of the region's one billion people live under seriously corrupt regimes, the impacts of corruption on economic growth are apparent.

\section{LITERATURE REVIEW AND THEORETICAL FRAMEWORK}

Existing as long as mankind, corruption is widely recognized both as a strength for action and as a quantified tangible item. According to the anticorruption organization, Transparency International (TI) defines it as 'the misuse of entrusted power for private benefits'. But in a broader and more current sense, we can further classify the corruption concept into three constituents to form part of the larger whole - corruption linked to the performance of one's duty, corruption in the form of economic exchange, and personal corruption ingrained in a societal setting. The use of influence is the common attribute to all these three forms and does exist in all levels of society, from the lowest class to the elites in power. The pervasiveness of corruption is entrenched within the three most important functions of society - Economic, Political and in the Cultural realms. Throughout history, some political elites have put forward suggestions for better government reforms, usually as a result of the situation they currently face. English Philosopher, and one of the founders of modern philosophy, Thomas Hobbes advocated a decisive "powerful leader", the view that all legitimate political power must be "representative" and based on the consent of the people. On the other hand, Italian politician and diplomat, Niccolo Machiavelli, stated that graft was essential to political survival. "Unless he withdraws from that general equality a number of the boldest and most ambitious spirits, and makes gentlemen of them ... by giving them castles and possessions, as well as money and subjects; so that surrounded by these he may be able to retain power." 
In the absence of strong democracy, rigged elections and a dependent judicial system, dictatorship is often the norm in Sub-Saharan Africa. The pattern of dictatorship in the region takes the most brutal of forms, that makes the unlawful seizure of assets (land, natural resources and financial institutions) necessary in order to reward the loyalty of political supporters. Since the majority of the companies operating in the natural resources sector are mostly foreign-owned enterprises (FOEs), the expropriation of natural resources does not, in any way, threaten the previous elite rung.

Lord Acton's short proverb, 'Power tends to corrupt, absolute power corrupts absolutely,' holds generally true - but slightly deficient as it does not illustrate the causality. The causal ties run both ways: power leads to corruption and corruption leads to power.

Viewing corruption from an economic lens and its effects on society's political will, it is imperative that we refer to the theory of political economist William Forster Lloyd who, in 1832, closely examined two different scenarios of the cattle that grazed on common land and the other that grazed on private property; where the former was not as fully developed as the latter. The whole logic behind this proposed theory is to show how selfish mankind is in his pursuit, and how it is often tied to political corruption. "On a common property, there is no motivation for a farmer to withhold his cattle from grazing in order to better serve another farmer". If a farmer is conscious of the longterm of over-grazing as collectively detrimental, his consciousness is soon after written-off after he realizes that he loses competitive advantage to his neighbour in the short-run if he withholds. Referred to as the "Tragedy of the Commons" theory by American Ecologist and Philosopher, Garreth Hardin assumes that once one party takes a self-interested advantage, others would be doing themselves a severe disservice if they held off "for the common good". This theory also reflects in the corruption of civil servants and government property as they are viewed to be owned by the state, with the freedom to unlimited use with little or no responsibility. This self-centred practice breeds a lack of care for government property, excessive embezzlement, and civic irresponsibility.

Sub-Saharan Africa is plagued with weak political institutions and a large number of unpredictable leadership, which serves as an incentive for the political elites to the sinister of wealth accumulation as they face continued uncertainty and fear of an unknown future. This staggering level of opportunism that pervades Post-Independent Sub-Saharan African economies is mainly the result of fairly poorly constructed, non-feasible and unsuitable institutional order.

The idea of corruption is not only an accidental phenomenon in the region but a stigma deeply rooted in the cultural norms and morality codes - with a usually oft-forgiving behaviour towards it. In the CPI (Corruption 
Perception Index) for 2017, Transparency International surveyed some 180 countries and the results revealed that: half of the bottom 25 nations in terms of heavily corrupt were in Africa while also having 0 of the top 25 least corrupt.

In the analysis, South Sudan and Somalia are interesting examples to cite - making the bottom two in global rankings with scores of 12 and 9 respectively. Nigeria's case is another puzzling one, on $148^{\text {th }}$ position, with all the potential of an economically strong nation in Sub-Saharan Africa. It overtakes the United States in oil reserves on a scale of $37,139 \mathrm{~m} / \mathrm{b}$ to 23,267 $\mathrm{m} / \mathrm{b}$. But regardless of this comparative advantage, the World Bank states "about 80 per cent of Nigeria's oil and natural gas revenues accrue to one per cent of the country's population...leaving Nigeria with the lowest per capita oil export earnings, at $\$ 212$ per person in 2004.”

Figure 1 - 2017 Corruption Perception Index

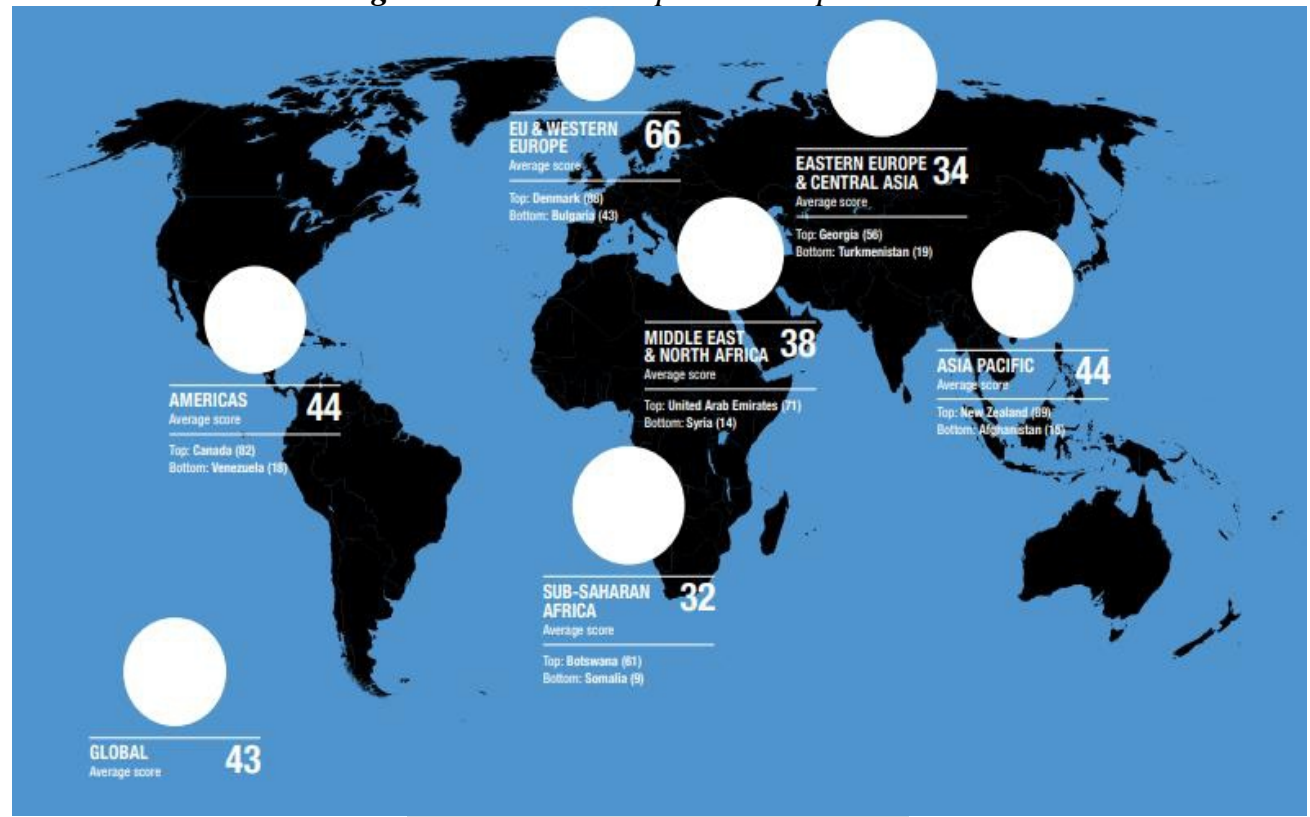

Source: Transparency International

Sub-Saharan Africa scores an average 32 points, with Somalia and South Sudan making the bottom least. The only impressive score of the report is Botswana's 61 points that topped the list in SSA. South Africa has fallen two places to go $9^{\text {th }}$, after claiming $7^{\text {th }}$ position with Senegal in 2016. 
Figure 2 - 2017 Sub-Saharan Africa Corruption Perception Index

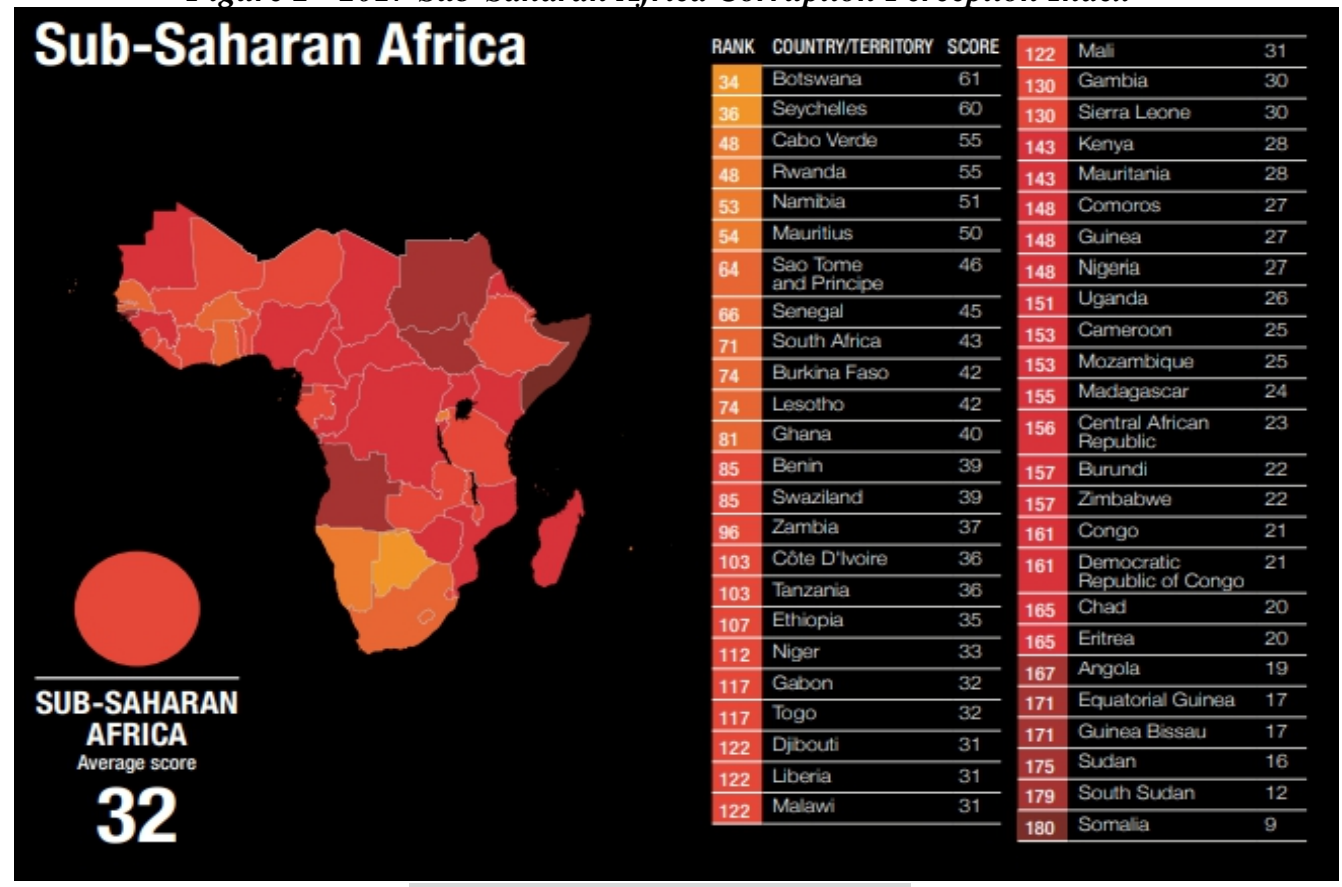

Source: Transparency International

Because corruption has gradually become an important and particular feature of society, however some Sub-Saharan Africans are conscious of this detriment to economic growth, thus this invites two obvious questions. Is corruption the product of inefficient checks on weak political institutions? Or does the culture of African anthropology permit corruption to fester within the political structures. The answer to these fundamental questions may be found in addressing both with the same degree of importance.

Justifying corruption will sound quite absurd to any sane man, but we must not rule out the fact that it does supplement the income of millions of people in Africa, where political and social support is usually lacking. If none, there only exist minimal national social welfare systems due to the presence of weak institutions. This is the number one incentive for those in position to secure as much wealth as possible for sustenance and those of their families. This act is not often viewed as corruption, but rather a norm for doing business in the continent.

Paolo Mauro, in 1995, suggested that corruption might increase growth through two fundamental mechanisms. Bureaucratic delays are likely to decrease if there is speed money corruption, and government workers are inclined to work even harder when they are allowed to take bribes. Both have significant effects on growth - either directly or indirectly. 
Nigerian Politician and Professor of Political Science, Wale Adebanwi, argues "Corruption occurs in both the public and private sectors, and public sector corruption may be both bureaucratic and political. Whichever way one views it, however, corruption is endemically rooted in human societies, especially those with weak institutions. Corruption in particular and maladministration generally are antithetical to societal progress and development. They breed inequality, undermine societal development, and retard progress."

Furthermore, Transparency International argued that corruption is "a social institution that is based on a principal-agent relationship that allows for frequent violation of formal or informal rules." This practice of 'getting things done' gains somewhat of a 'legal status' through time as it becomes deeply ingrained in society's attitudes. This does not, however, write-off the moral hazard.

\section{Principal-Agent Model}

Also known as the "agency dilemma", this is a standard theory applied to corruption within society. This occurs when one or entity called the "agent" is able to make decisions on behalf of, or that impact, another entity the "principal". While it is widely perceived as immoral or criminal, the "principal" offers payment in monetary terms or kind to a public servant, referred to here as the "agent" as a reward for the favour. How do we clear the doubt or validate this ethical misconduct? Has the agent betrayed public trust by using influence or power to their own ends to grant favour? Or should we call the offer from the principal a temptation the agent could not shy away from? The answer goes both ways, for political elites in Africa are heavily dependent on corruption to cling on to power; whilst the masses get on with the practice to make ends meet. Most Africans see no incentive to desist from corruption as the abstinence brings in no change. What this widely held yet rather poor belief is suggestive of the economic principal stated in the "Tragedy of the Commons", a situation in a shared-resource system where individual users acting independently according to their own self-interest behave contrary to the common good of all users by depleting or spoiling that resource through their collective action. The figure below clearly describes this phenomena. 
Figure 3- Principal - Agent Model
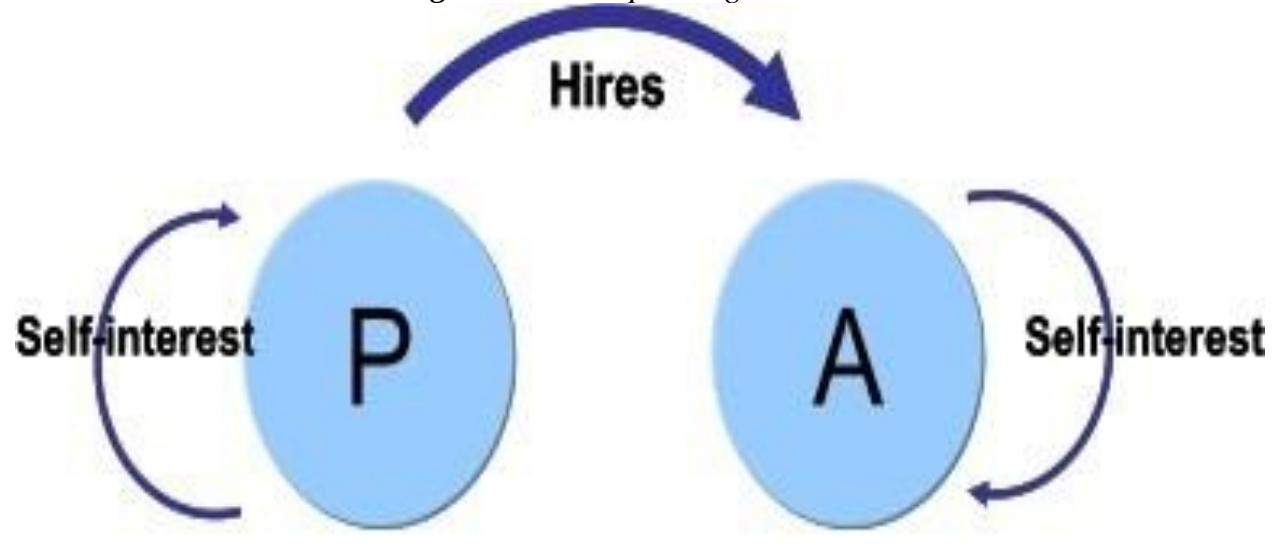

\section{Performs}

Source: VIVIFYCHANGECATALYST

The question of whether African Culture is to blame has often been raised. Culture, without any iota of doubt, does play a significant role in widespread corruption across the continent, but attributing it as endemic only to Sub-Saharan Africa would sound quite prejudiced and biased reasoning.

\section{The Impact of Corruption in the Region}

Sub-Saharan African countries will continue to fail and be at the mercy of the world if the impact of corruption is underestimated. Numbers has it that almost half the population of the region is living under abject poverty, while annual stolen assets that flow out of the region to offshore tax havens is well over $\$ 50$ billion; a staggering amount that could be used in job creation and improvement of social services. Extensive corruption schemes substantiate prevalent lack of development in the region, which does not only drive away investors but as well deters development.

The corruption syndrome does not spare individuals and families as most have to pay bribes before they are offered public service.

\section{Solutions to the Corruption Cause}

In an open letter to the African Union dated $11^{\text {th }}$ July 2018, Transparency International together with 28 African chapters highlighted seven key areas where the African Union should put strenuous efforts in to mitigate corruption if not completely eradicated:

- Financial support. Funding must match commitments to help strengthen existing anti-corruption systems and support civil society. 
- Treaty ratification. The countries that haven't done so must ratify the AU Convention to Prevent and Combat Corruption, a shared roadmap implementing governance and anti-corruption policies.

- Internal investigation. Recent allegations of corruption within the AU Advisory Board on Corruption and throughout various departments of the AU should be investigated and any wrongdoers should be punished.

- Procurement. The AU should develop minimum standards and guidelines for ethical procurement and build strong procurement practice throughout the continent with training, monitoring and research.

- Open contracting. Open contracting practices, which make data and documentation clearer and easier to analyse, should be adopted by all African countries.

- Stolen assets. Governments should create and enforce laws that address the proceeds of corruption, crime and money laundering.

- Shell companies. Private companies sometimes keep their owners' names secret, allowing for criminal activities and dirty money to go untraced. AU countries should establish public registers that name these individuals and thoroughly vet bidders for public contracts.

\section{Conclusion}

To expect a difficult-free transition from an under-performing to a functioning and well-diversified economy characterized by government transparency is like living a world of fantasy. There still exists divided political and economic landscape in SSA, and the region is continually ravaged by a descent into anarchism and fractionalization.

The proposition that the quality of political institutions is a measure of responsible political stewardship infers that a correlation exists between leadership and economic development.

It is evident to adduce that SSA's socio-economic development is just a fraction compared to the extensively large degree of embezzlement and corruption. This does not only create regular patterns of intense and selfish desire for power and wealth, but also a cycle of anarchy. At this fundamental stage in SSA's desperate need for economic transformation, it is imperative that resource-endowed nations take the lead - as facilitators essential for economic growth.

\section{References:}

1. 2015a. "Africa Overview". The World Bank Group Accessed January 12th 2016. http://www.worldbank.org/en/region/afr/overview

2. Adebanwi, W. and Obadare, E. (2011), "When corruption fights back: democracy and elite interest in Nigeria's anti-corruption war", Journal of Modern African Studies, Vol. 49, pp. 185-213. 
3. Arezki, R. and Gylfason, T. (2013), "Resource rents, democracy, corruption and conflict: evidence from Sub-Saharan Africa", Journal of African Economies, Vol. 22 No. 4, pp. 552-569.

4. Barrat Brown, Africa's Choices 3.

5. Bruce Bueno De Mesquita and Alastair Smith, The Dictator's Handbook: Why Bad Behavior is Almost Always Good Politics, (New York: Public Affairs 2011), p.91

6. Collier and Gunning, "Why Has Africa Grown Slowly?," 3-22

7. Dambisa F. Moyo, Dead Aid: Why Aid is Not Working and how there is a Better War for Africa, 1st ed. (New York: Farrar, Straus and Giroux, 2009), 31.

8. Dani Rodrick, An African Growth Miracle? Richard H. Sabot Lecture, April 2014, JEL No. O11,O40,O55 http://www.nber.org/papers/w20188.

9. Daniel Egiegba Agbiboa, "Serving the Few, Starving the Many: How Corruption Underdevelops Nigeria and How There is an Alternative Perspective to Corruption Cleanups" Africa Today, Vol. 58 Issue 4, (Summer2012) p.112

10. http://www.oecd.org/newsroom/development-aid-stable-in-2017with-more-sent-to-poorest-countries.htm

11. https://www.corruptionwatch.org.za/wpcontent/uploads/2018/02/Global_Report_2017_final_web_NEW.pdf

12. https://www.transparency.org/news/feature/how_to_win_the_fight_a gainst_corruption_in_africa

13. Lalountas, D., Manolas, G. and Vavouras, I. (2011), "Corruption, globalization and development: how are these three phenomena related?", Journal of Policy Modeling, Vol. 33 No. 4, pp. 636-648.

14. Lawson, L. (2009), "The politics of anti-corruption reform in Africa", Journal of Modern African Studies, Vol. 47, pp. 73-100.

15. McFerson, H. (2009), "Governance and hyper-corruption in resource-rich African countries", Third World Quarterly, Vol. 30 No. 8, pp. 1529-1547.

16. Mojeed Olujinmi Alabi, "Extra-Territorial Approach to AntiCorruption, Integrity and Public Service Ethics in Africa: A Review of Frameworks and Implementation Challenges." Journal of Alternative Perspectives in the Social Sciences, Vol. 2 Issue 2, (Dec2010): p.502

17. Moss, African Development, 204.

18. Rothstein, Bo (2011), The Quality of Government: Corruption, Social Trust, and Inequality in International Perspective, University of Chicago Press, Chicago, IL

19. Senyo Adjibolosoo, "Economic Underdevelopment in Africa: The Validity of the Corruption Argument", Review of Human Factor 
Studies, Vol. 11 Issue 1,(Jun2005): p.105

20. The Economist. 2015, "The scale of corruption in Africa" 